Article

\title{
Communication Machines as Art
}

\author{
Ernest Edmonds
}

IOCT, Leicester Media School, De Montfort University, The Gateway, Leicester LE1 9BH, UK; ernest@ernestedmonds.com

Received: 30 December 2018; Accepted: 4 February 2019; Published: 9 February 2019

Abstract: The paper presents a personal history of making machines as artworks. The particular kind of art machines that have been made since around 1970 are communication machines: ones that enable humans to interact with each other. However, they do not provide communication in the normal sense, but use a small bandwidth for relatively complex connections, making the experience of the interactions the art experience. The paper concludes by explaining how it later became possible to use computer networking and the Internet to make artworks that were more complex and, in part, autonomous generative machines whilst retaining the earlier communication machine functions.

Keywords: art; computer; communication; machine

\section{Introduction}

The paper follows an earlier one in this journal in which I described my personal development in relation to art made by algorithmic machines (Edmonds 2018a). For completeness, I will repeat a few of the points made in that earlier description. However, this paper deals with a different aspect of that personal development. In this case, I will review my art that is about human-to-human communication through machines. So the algorithm in the machine, that is central to that other stream of work, is not the point here. Instead, machines have been constructed as artworks through which people communicate with one another. The forms of communication are not linguistic, or meaningful in that explicit sense, but nevertheless what one person sees or hears in the machine is determined by the actions of others. These art works are communication machines, machines that, when operated at least, are art. I presented a paper at a 1970 Computer Graphics conference, Computer Graphics '70, together with Stroud Cornock. It was titled "The Creative Process where the Artist is Amplified or Superseded by the Computer". We discussed the implications of the computer for art and for the role of the artist. We asked: would this machine become the artist of the future? Would the artist of the future have any role at all? The paper was later published in Leonardo (Cornock and Edmonds 1973). Although not discussed in that paper, I was also asking a closely related question: would the machine become the art? The context in which I was asking this last question was communication. As I will explain, I had become interested in human-to-human communication processes and I saw one route forward in my exploration of the computer and art in communication machines. The paper will show how this began using purpose-built logic circuits rather than computers as such and how it has developed into Web-based art machines.

This paper discusses a certain path in the history of interactive art and discusses the context of that history. Whilst considering the works reported, a number of other, non-historical, research questions come to mind. Some of these have been investigated and such work is briefly introduced in Section 5. 


\section{Machines (as Art)}

A machine can be defined as "a piece of equipment with several moving parts that uses power to do a particular type of work"1. Today, the notion of "equipment with several moving parts" is taken to include electronic devices, such as the computer. There is expected to be a clear task that a machine should undertake and normally its operation is deterministic: it will always operate in the same way. Another important characteristic of a machine is that it needs a human operator who, at the very least, sets it going. Until it is "going" a machine has little meaning. If we take an interest in the aesthetics of a machine, then that can only be considered when the machine is in action (Edmonds 1987). As Werner Gräff said of the 1925 Berlin bus, " . . the shape of a vehicle must be preserved above all when it is in motion ... OUR NERVES demand PNUMATIC TYRES ... And our aesthetic sense too" (Gräff 1926).

A machine that is art is a working machine that is doing something. We might argue, taking this point further, that the art in an art machine is in what it does much more than in how it looks. Perhaps how it looks is of little concern at all. One perspective on machines as art is to consider them doing something that creates the aesthetic experience that defines the art. It is this view that informs the kind of machine as art that I am reporting here. The machines that I have built and that I describe below are electronic machines, sometimes using computers. Their appearance is often not material. It is primarily the experiences that they facilitate in the audience that is at the core. In this case the audience consists of the operators of the machines, so we would normally call them the participants. The art forms of my machines discussed in this paper are particular cases of interactive art, forms in which the interaction is between different participants through the machines.

\section{The Communications Game Concept}

At the same time that Stroud Cornock and I were discussing what became the Computer Graphics '70 conference paper referred to above, I was following psychological research about language and learning. I was most influenced by the work of T.G.R. Bower. He neatly described the key points in a book a little later (Bower 1974). As I have described elsewhere, my focus was on a notion of communication that "was one of meaningful interaction in the sense of, for example, the ways that T.G.R. Bower found that newborn infants explored the world around them. They took actions, observed what happened and, in a very real sense, seemed to form theories that could be tested. They began learning how to communicate through the exploration of actions purposefully taken." (Edmonds 2016). The exploration of interactive art using computers, that was at the heart of the Cornock and Edmonds paper, informed my thinking about this early infant behavior: about the early communications with the world that a newborn makes. Perhaps I could make interactive art, in some sense, that explored these psychological findings about learning to communicate?

My concept was to build an art machine that in itself had no aesthetic, or other, interest but that facilitated some kind of low bandwidth exchange between people, where the involvement in that exchange was the art work experience. The machine I devised was called a Communications Game. I used the label "game", not because there was any "computer game" or party aspect to it but so as not to stress my intention to make "art" and so risk participants putting barriers up.

The idea was to provide very simple communication networks between participants who could not see one another. Each participant would access Communications Game through their own unit or station. A way of adding a small amount of complexity, that to me seemed to be a vital part of the real world, was to have at least three participant units and for the networks to cross over, so that there was only ever a partial direct link. Thus each unit was to be equipped with an input switch for turning on lights in units of the same network and a single light for output. For each participant, the lights provide the stimuli and the switches, the means of action or response. As I indicated, screens would

1 Machine, definition, Cambridge Dictionary: https://dictionary.cambridge.org/dictionary/english/machine (accessed on 28 December 2018). 
keep participants from seeing each other. The illumination of a light on one unit is controlled by the other participants by opening or closing their switches. The truth table shown in Figure 1 shows how I planned one configuration to work, where for example a person at A can control switch A and sees light A.

\begin{tabular}{|c|c|c|c|c|c|c|c|}
\hline \multicolumn{4}{|c|}{ SWITHES } & \multicolumn{3}{|c|}{ LISHTS } & \multirow[b]{2}{*}{ D } \\
\hline A & $B$ & c & D & A & $B$ & $c$ & \\
\hline 0 & 0 & 0 & 0 & 0 & 0 & 0 & 0 \\
\hline 0 & 0 & 0 & 1 & 1 & 1 & 1 & 0 \\
\hline 0 & 0 & 1 & 0 & 1 & 1 & 0 & 1 \\
\hline 0 & 0 & 1 & 1 & 0 & 0 & 1 & 1 \\
\hline 0 & 1 & 0 & 0 & 1 & 0 & 1 & 1 \\
\hline 0 & 1 & 0 & 1 & 0 & 1 & 0 & 1 \\
\hline 0 & 1 & 1 & 0 & 0 & 1 & 1 & 0 \\
\hline 0 & 1 & 1 & 1 & 1 & 0 & 0 & 0 \\
\hline 1 & 0 & 0 & 0 & 0 & 1 & 1 & 1 \\
\hline 1 & 0 & 0 & 1 & 1 & 0 & 0 & 1 \\
\hline 1 & 0 & 1 & 0 & 1 & 0 & 1 & 0 \\
\hline 1 & 0 & 1 & 1 & 0 & 1 & 0 & 0 \\
\hline 1 & 1 & 0 & 0 & 1 & 1 & 0 & 0 \\
\hline 1 & 1 & 0 & 1 & 0 & 0 & 1 & 0 \\
\hline 1 & 1 & 1 & 0 & 0 & 0 & 0 & 1 \\
\hline 1 & 1 & 1 & 1 & 1 & 1 & 1 & 1 \\
\hline
\end{tabular}

Figure 1. Truth table drawing, Communications Game (c. 1970), (c) Ernest Edmonds.

The Communications Game machine was not defined as any particular physical object. I defined it functionally but was very clear that it could be realized in many different ways. See my note from that time, for example, the "specification" remark in Figure 2. I was emphatic that this was not to be an aesthetic physical object. It was not a crucial issue that it should look a particular way, be in a particular color or be made of a particular material. In a sense, the art was conceptual but the point was that the art was the machine in action, providing the interchange between people that I termed, perhaps rather grandly, "communication". The concept of this work was of a particular machine that was the art, at least once it was in action. By definition, however, there was never meant to be only one physical object. As with most machines, it could be copied, varied and reproduced, as I will describe below. 


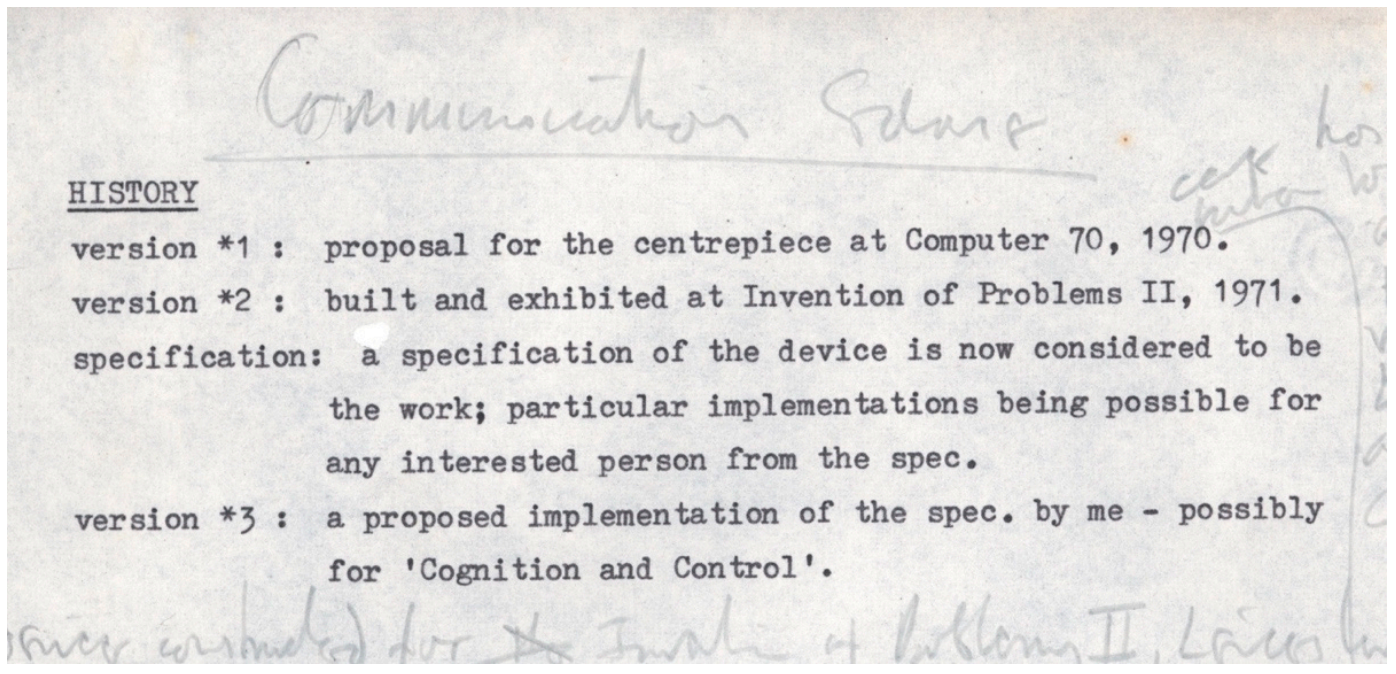

Figure 2. Notes about Communications Game (c. 1971). (c) Ernest Edmonds.

\section{Realizing Communications Games}

The first Communications Game that I constructed was shown in the Invention of Problems II Exhibition at the City of Leicester Polytechnic in 1971. The work has six stations and there are three networks of three units. Screens kept the participants apart. The general physical arrangement is shown in Figure 3.

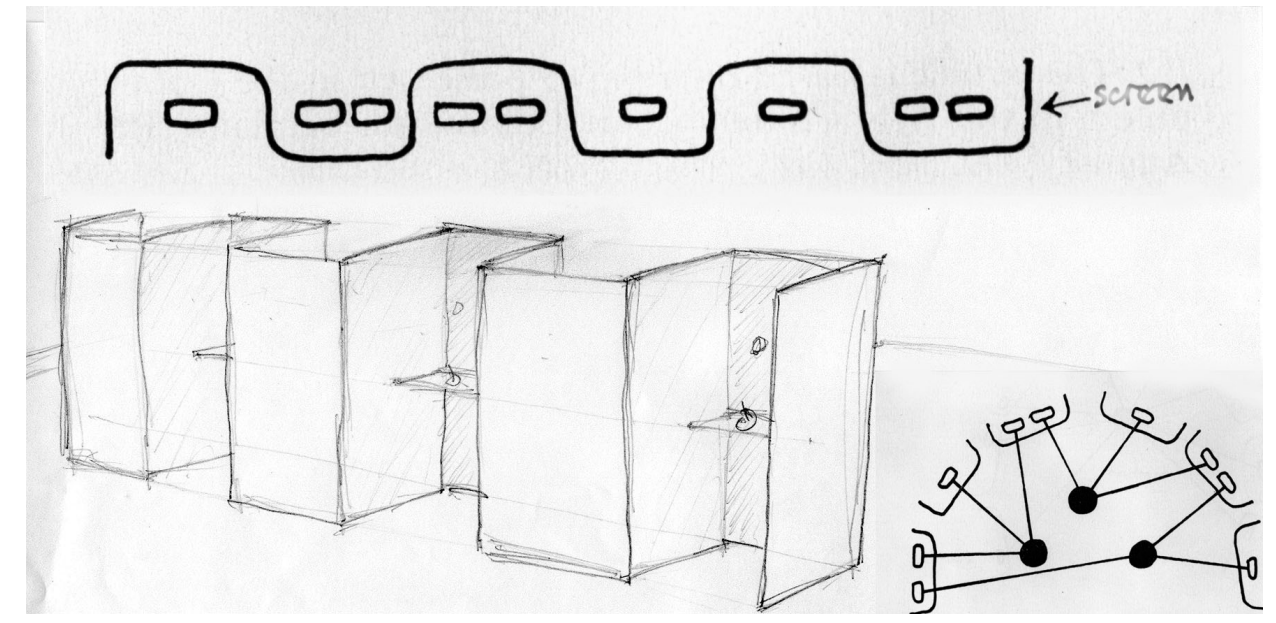

Figure 3. Sketches of the Communications Game layout (c. 1971). (C) Ernest Edmonds.

I designed electronic circuits to implement the connection logic of the networks, along the lines of the truth table in Figure 1. The actual construction of the connection logic, at that time, involved the use of a soldering iron rather than software, as is more convenient today.

In 1972 I was invited to show in the exhibition organized in Nottingham by Stephan Willats, Cognition and Control at the Midland Group Gallery (Edmonds 1972, 1975). For this, I constructed a second version that accommodated three, rather than six, participants. My informal evaluation of the first version was that it was rather over complex and I felt that reducing the number of stations, whilst retaining the rest of the design as before, improved the work. See Figure 4. 


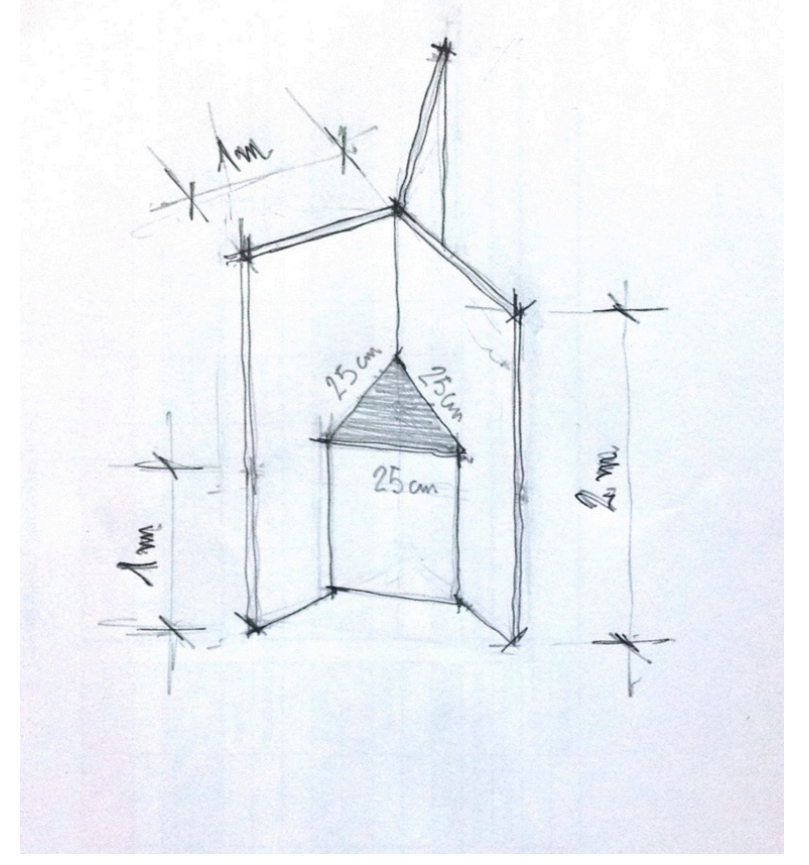

Figure 4. Sketch of Communications Game version 2 (c. 1972). (c) Ernest Edmonds.

A little later, I made a three-station version which used sound output rather than lights. Three boxes were installed in different parts of an informal exhibition, also at Leicester Polytechnic. Figure 5 shows part of the circuit diagram used in this version.

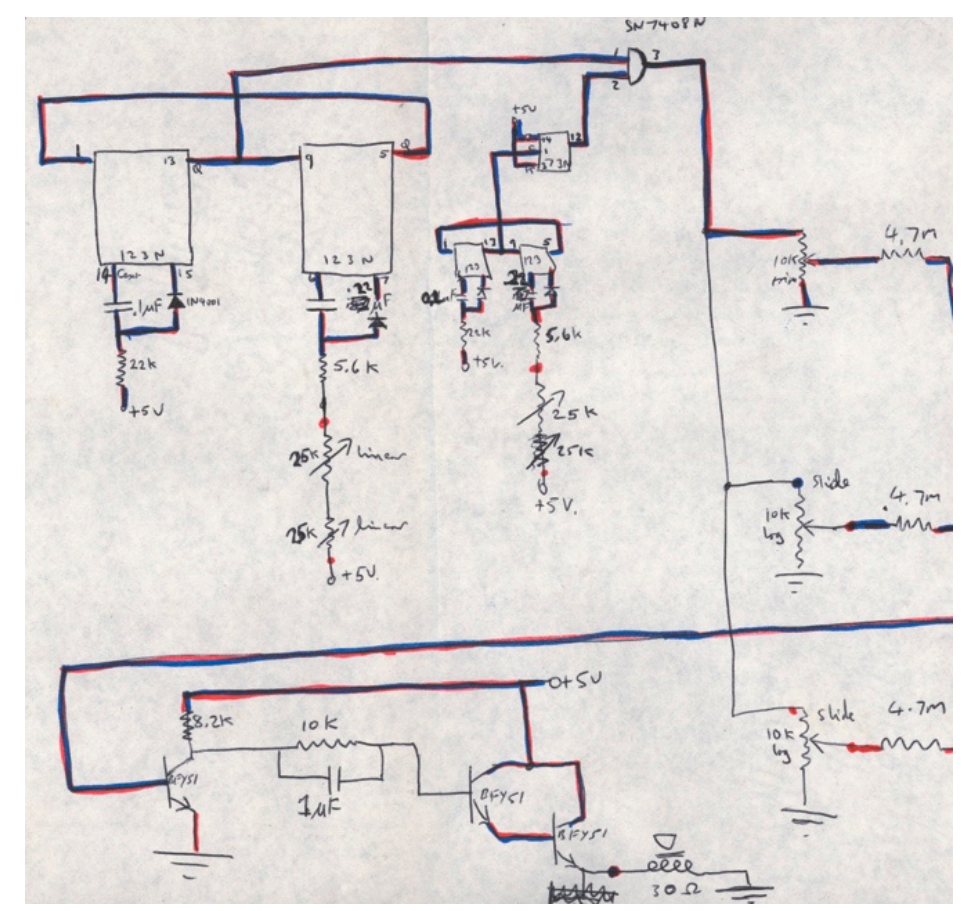

Figure 5. Circuit diagram (detail) of Communications Game with sound output (c. 1972). (C) Ernest Edmonds.

I left my work on communication art machines aside for quite some time, until 1990, when Willats invited me to show in his Art Creating Society exhibition at what was then called the Museum of Modern Art, Oxford. By now, I could build networks in software, of course, and I built a new version in which each participant saw a screen rather than lights. The screen showed a sequence of images 
based on my Fragment video construct. See Figure 6 and more about Fragment in Edmonds (2018a). The operations performed by other participants changed the image sequence. The network, in this version, contained a number of computers as shown in Figure 7. I had intended to make the stations remote by using wide area network connections to a VAX computer in Oxford, but the collaboration was not sealed in time and that aspect was not realized. The use of wide area networks had to wait until the next phase, as described in Section 4.

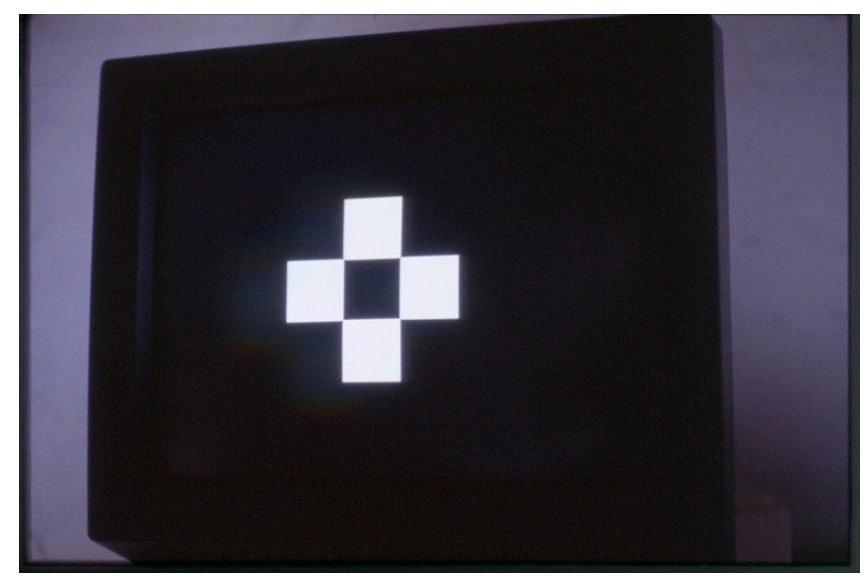

Figure 6. Fragment 1984-5, still from the exhibition 'Duality and Co-existence' Exhibiting Space, London, 1985. Photo Ernest Edmonds, ( E Ernest Edmonds.

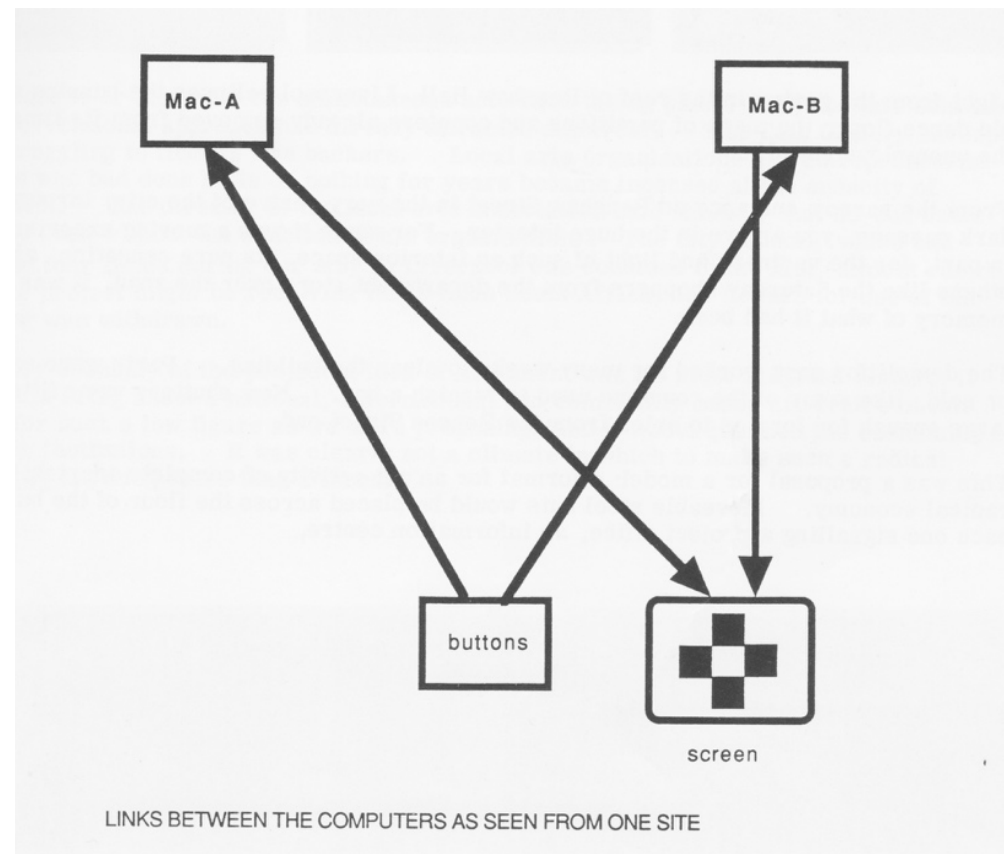

Figure 7. Diagram of one unit of Communications Game in the 'Art Creating Society' exhibition, 1990. Illustration from Edmonds (1990).

Much later I started to hold retrospective exhibitions of various kinds and it became useful to construct new implementations of Communications Game. I used the second, Cognition and Control, version for these reconstructions. The first was shown in 2015 in the Códigos Primordiais (Primary Codes) exhibition at Oi Futuro Flamengo, Rio de Janeiro (Poltronieri and Menezes 2017). The electronics was reproduced to function exactly as in 1971, but this time implemented in software on Arduino computers. Visually, it looked very similar to the earlier version, see Figure 8. 


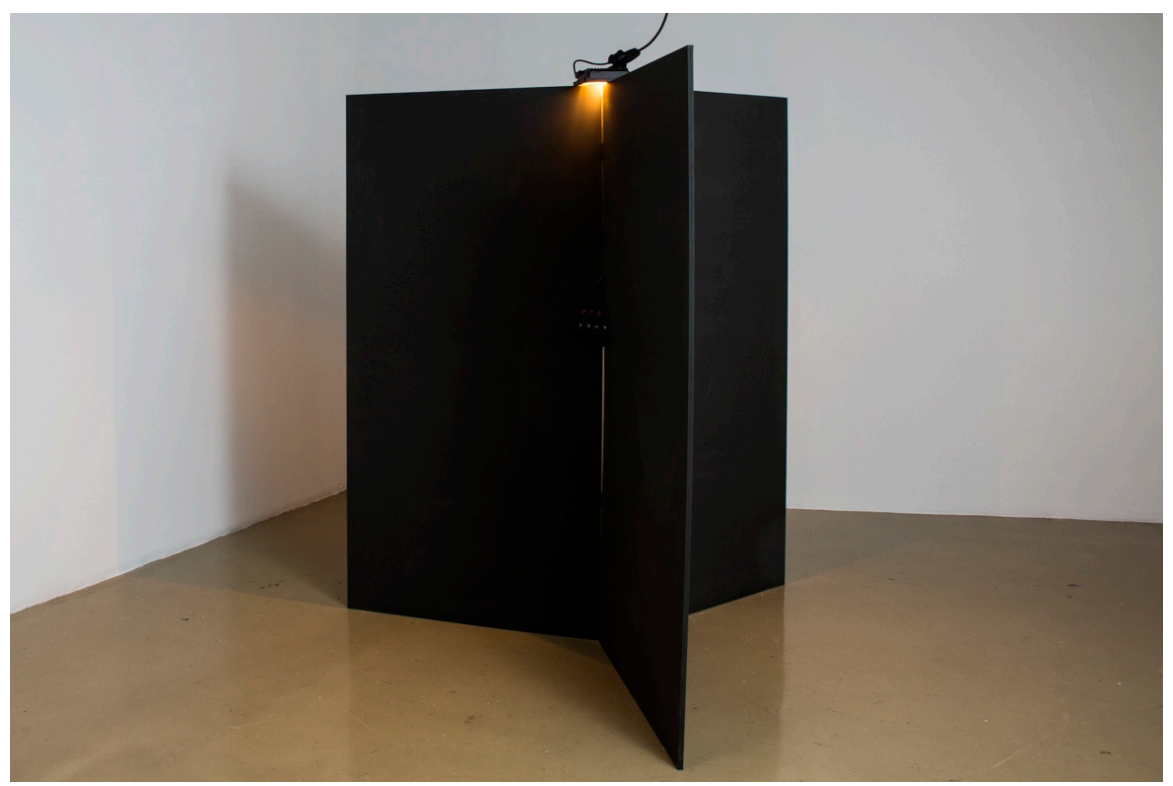

Figure 8. Communications Game in the 'Primary Codes' exhibition. 2015. Photo Ernest Edmonds. (C) Ernest Edmonds.

A very similar reconstruction was shown in 2017 at a one-person retrospective, Constructs Colour Code: Ernest Edmonds 1967-2017 in The Gallery, De Montfort University, Leicester.

\section{Communications Game Machines and the Internet}

Historically, the time when I first developed my Communications Game machines was just as the the first working version of ARPANET, the Internet's predecessor, was put together, in 1969 (Leiner et al. 1997). Of course, the idea of an electronic, computer-based network had been under discussion for some time but the Internet itself awaited the key concepts published in 1974 (Cerf and Kahn 1974). Although Communications Game was a machine concept developed before Internet art, it was natural to think about implementing it on the Internet once it was available. However, I never considered making a simple direct version.

I reflected on my Oxford experience of making the computer-based version that employed a local area network and worked towards an extension of the concept. Eventually I started to make a series of works, called Cities Tango, that were distributed widely over the Internet (Edmonds and Franco 2013). Briefly, images from remote location are dynamically shown within an otherwise abstract colour structure. The images are treated as abstract objects within the work. The colours used and the pace of the work are influenced by a combination of the audience behaviours at the various locations.

Cities Tango is not a simple machine like Communications Game. It incorporates a different interaction paradigm drawn from my Shaping Form pieces. These are individual works, first exhibited in 2007 in Washington, DC (Jennings 2007). In these, images are generated using rules determining the colours, the patterns and the timing. The generative works are also changed by inputs from the environment: movement is detected and causes continual changes to the rules, so that changes are made to the generative process. Thus, many of the changes are only apparent over time. A first viewing followed by another weeks or months later will reveal noticeable developments in the colours and patterns. The Shaping Form works might be considered machines, but they are not machines in the sense focused upon in this paper. Therefore, by combining Communications Game with Shaping Form, Cities Tango demonstrates a more complex machine form.

In one example of Cities Tango, the cities, Belfast and Sydney, interacted with one another (Edmonds 2009). The colours, shapes and timings used at one location were driven by movements at the remote one. Sometimes, real-time images from the remote location are shown. Immediate responses to movement in the remote location are seen by participants in their own location. See 
Figures 9 and 10. Further developments have been made in collaborative projects (Edmonds and Clark 2016).

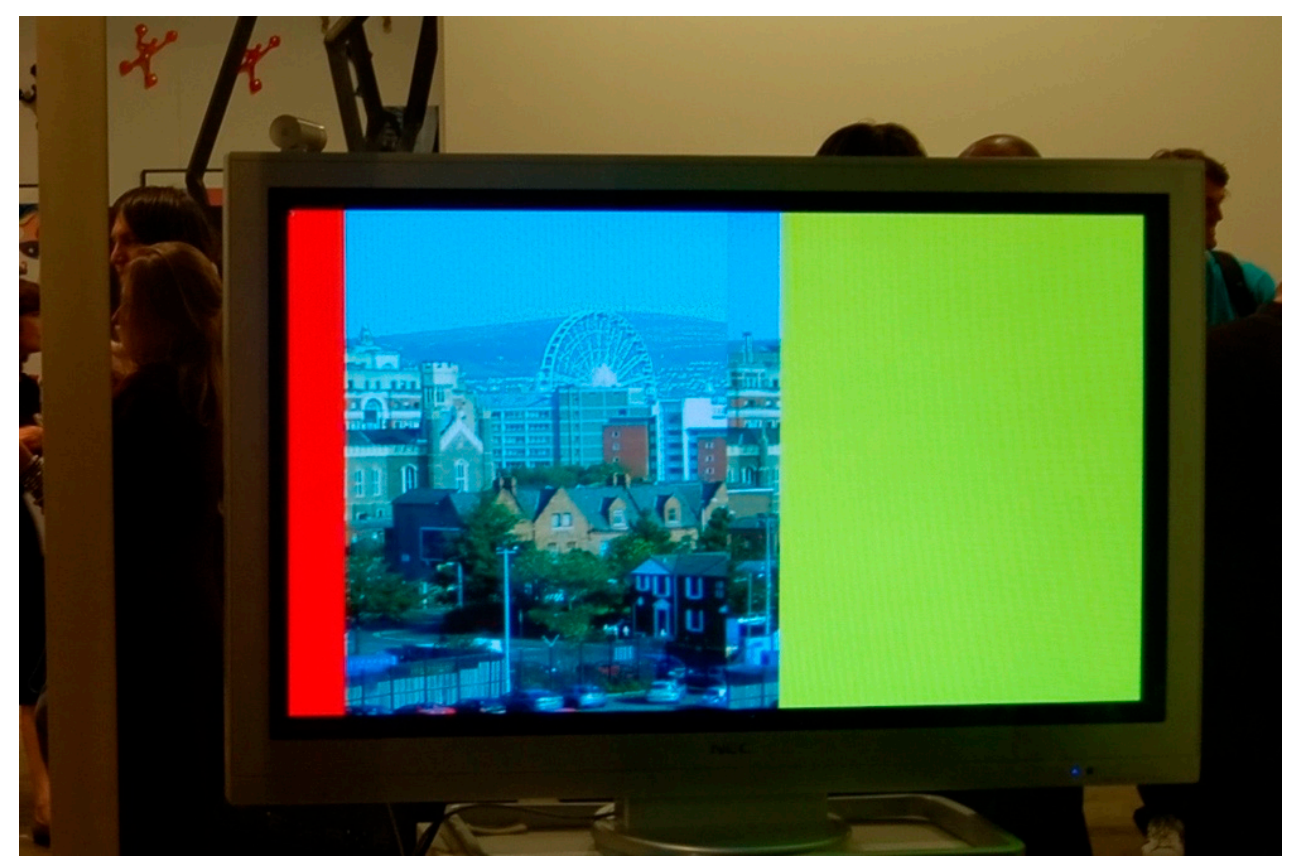

Figure 9. Cities Tango in Sydney. 2009. Photo Ernest Edmonds. @ Ernest Edmonds.

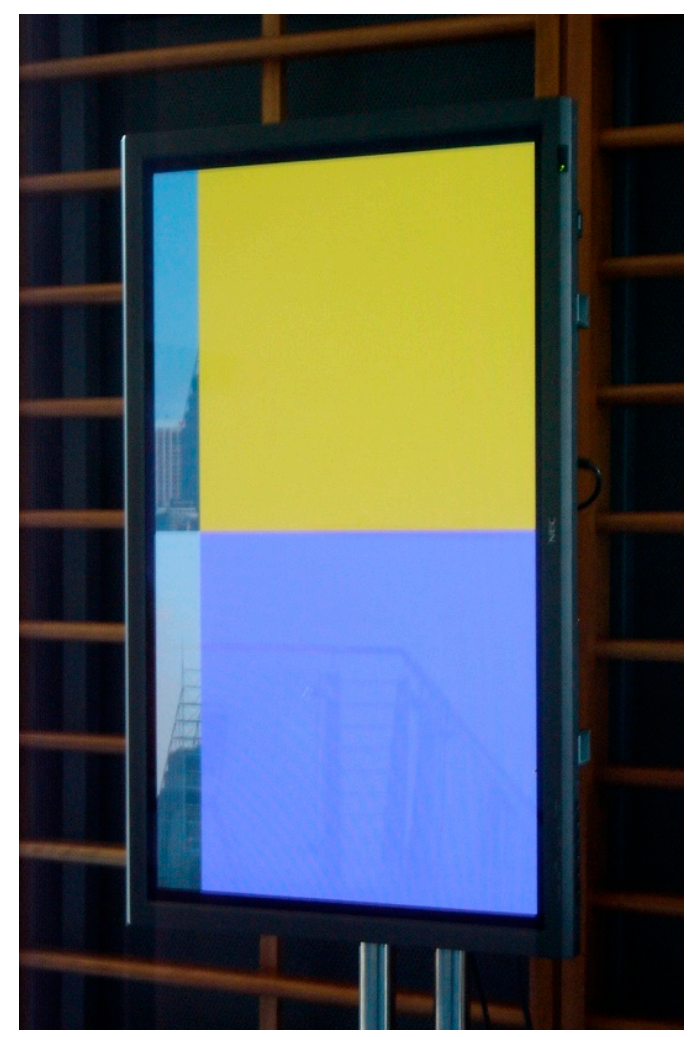

Figure 10. Cities Tango in Belfast. 2009. Photo Ernest Edmonds, ( Ernest Edmonds.

These works include the communication machine functions discussed above but they are overlaid on a generative process that is independent of any "operator" (participant) action. The Cities Tango works are still machines, so "machines as art", but they have partial autonomy and so are more complex than the machines I made in the 1970s. 


\section{Research Questions Arising from this History}

The primary contribution of this paper is historical but, as the new art forms described above were invented and explored, various research questions arose. Indeed, as I have explained, the initial impetus arose from research in psychology. However, the questions that the work gave rise to, were from the practice-based research viewpoint (Candy and Edmonds 2018) and related more to computer-human interaction than to psychology itself. A full review of such research, from a broader context, is the subject of a recent book that emphasizes how much computer-human interaction research can learn from interactive art research (Edmonds 2018b). I will now give a flavor of research relevant to the art reported in this paper.

Specific issues relating to the artwork Communications Game and its developments, technical matters aside, include two main classes of research question: (1) what are the experiences of and influences on the artist, and (2) what are the experiences of the participating audiences?

In relation to the first class of question, I have documented my reflections in the classic practice-based research manner. As yet, most of that research has not been published but, briefly, the key points to note are:

- The early (1970s) concentration on interaction between participants clarified and strengthened an inclination to see the artwork as a conceptual object.

- It became impossible to complete such artworks without seeing versions of them in action, in the field. This led to the development of a beta-testing element in the art-making process and to the Beta_Space initiative, as described for example in Candy and Edmonds (2011), in which interactive artworks were shown and evaluated in a live museum exhibition setting.

- The use of the Internet to build distributed communication artworks (art systems) introduced new concerns such as dealing with time, climate and cultural shifts within a single work.

In relation to the second class of question, I should first emphasis that the intended experiences are aesthetic, art, ones. Hence they do not relate to any task or purpose, which would be expected in a more typical computer-human interaction case. The methods used for these studies are those described in two books (Candy and Edmonds 2011; Candy and Ferguson 2014). Those books include various examples of those methods in use together with descriptions of the results.

A specific relevant case of such research was an empirical study of an interactive public installation of an early element of Cities Tango (Bilda et al. 2017). The interactions (driven by sound pickup up by a microphone) were quite abstract and participants were at times inclined to "think of sound waves, sunshine and the horizon. Other participants felt happiness, liveliness, a festive or party feel; while still others thought of rhythm and music or a discotheque". A small number of "participants stated that they would have engaged more comfortably if it was in a museum/art gallery context, and that they would prefer an enclosed space with a feeling of an individual experience rather than an open and social one", and "one stated he became self-conscious when he thought he was being monitored". These last two concerns relating, in one way or another, to privacy are of on-going and increasing interest. The future of art of the kind described above must address such concerns, which can indeed become one of the subjects that the art addresses.

The art history described in this paper is one that has led to a particular stream of research about artist and audience experience that is increasingly strong. To review it would require a second paper, at the very least, and here I simply wanted to acknowledge that outcome and point to some of the resulting work.

\section{Conclusions}

I have presented a personal history of the making of machines as art. The particular machines that I have made, I have termed "communication machines". The term "communications" has only been used to indicate that participants interact with one another through the machines. There is no suggestion or intention that meaningful communication in any deep sense takes place. The interaction 
is aesthetic. It is the art experience. These machines are not of any particular aesthetic interest as objects, only as machines whose operation is being used by the participants. Communications Game was a pre-Internet concept but, in the later part of the paper, I indicate how I developed the idea to both employ the Internet over large distances and incorporate generative, autonomous, approaches from my Shaping Form works, thus making the Cities Tango series. A full discussion of my work is available in Francesca Franco's book (Franco 2018).

Acknowledgments: I am grateful to Sean Clark for his help in reconstructing Communications Game for the 2015 and 2017 exhibitions. As I was preparing the final version of this paper I discovered that Stroud Cornock had sadly passed away. His collaboration and many conversations inspired much of the work that I have done over the fifty years since we first met.

Conflicts of Interest: The author declares no conflict of interest.

\section{References}

Bilda, Zafer, Ernest Edmonds, and Deborah Turnbull. 2017. Interactive experience in a public context. In Proceedings Creativity and Cognition 2007. New York: ACM, pp. 243-44.

Bower, T.G.R. 1974. Development in Infancy. San Francisco: Freeman.

Candy, Linda, and Ernest Edmonds, eds. 2011. Interacting: Art, research and the Creative Practitioner. Oxford: Libri Press.

Candy, Linda, and Ernest Edmonds. 2018. Practice-based research in the creative arts: Foundations and futures from the front line. Leonardo 51: 63-69. [CrossRef]

Candy, Linda, and Sam Ferguson, eds. 2014. Interactive Experience in the Digital Age: Evaluating New Art Practice. London: Springer.

Cerf, Vinton G., and Robert E. Kahn. 1974. A protocol for packet network interconnection. IEEE Transactions on Communication Technology 22: 627-41.

Cornock, Stroud, and Ernest Edmonds. 1973. The creative process where the artist is amplified or superseded by the computer. Leonardo 16: 11-16. [CrossRef]

Edmonds, Ernest. 1972. Communications game. Control Magazine 6: 14.

Edmonds, Ernest. 1975. Art systems for interactions between members of a small group of people. Leonardo 8: 225-27. [CrossRef]

Edmonds, Ernest. 1987. Good software design: What does it mean? In Human-Computer Interaction: INTERACT '87. Edited by Hans-Jörg Bullinger and Brian Shackel. Amsterdam: Elsevier, pp. 333-35.

Edmonds, Ernest. 1990. Video construct communication systems. Control Magazine 14: 14.

Edmonds, Ernest. 2009. Cities Tango: Between Belfast and Sydney. In Catalogue ISEA2009. Coleraine: University of Ulster, p. 66.

Edmonds, Ernest. 2016. Network art from the birth of the internet to today. Acoustic Space 15: 80-87.

Edmonds, Ernest. 2018a. Algorithmic Art Machines. Arts 7: 3. [CrossRef]

Edmonds, Ernest. 2018b. The Art of Interaction: What HCI can learn from Interactive Art. San Rafael: Morgan and Claypool.

Edmonds, Ernest, and Stroud Clark. 2016. Tango Apart: Moving Together. In CHI EA'16 Extended Abstracts on Human Factors in Computing Systems. New York: ACM, pp. 3663-66.

Edmonds, Ernest, and Francesca Franco. 2013. From communications game to cities tango. International Journal of Creative Computing 1: 120-32. [CrossRef]

Franco, Francesca. 2018. Generative Systems Art: the work of Ernest Edmonds. London: Routledge.

Gräff, Werner. 1926. On the form of the motor car. Die Form 1: 195-201. Translation in Tim Benton. 1975. In Form and Function. London: Crosby Lockwood Staples, pp. 242-44.

Jennings, Pamela. 2007. Catalogue: Speculative Data and the Creative Imaginary. Washington: National Academy of Sciences Gallery. 
Leiner, Barry M., Vinton G. Cerf, David D. Clark, Robert E. Kahn, Leonard Kleinrock, Daniel C. Lynch, Jon Postel, Larry G. Roberts, and Stephen Wolff. 1997. Brief History of the Internet. Available online: https://www. internetsociety.org/internet/history-internet/brief-history-internet/ (accessed on 18 December 2018).

Poltronieri, Fabrizio, and Caroline Menezes. 2017. Primary Codes. São Paulo: Caosmos.

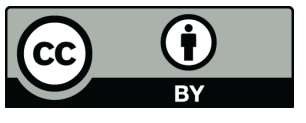

(C) 2019 by the author. Licensee MDPI, Basel, Switzerland. This article is an open access article distributed under the terms and conditions of the Creative Commons Attribution (CC BY) license (http://creativecommons.org/licenses/by/4.0/). 